\title{
Standing Committee on Postgraduate Medical Education disquieted by threats to training
}

Working for Patients is committed to improved quality of care and greater choice for patients, but its proposals have not been costed and are not based on formal studies. The Standing Committee on Postgraduate Medical Education is disquieted that much of the white paper's content and the way in which it has been launched will threaten postgraduate medical and dental education. In its response to the white paper the standing committee warns that the timescales for consultation and implementation are too short, responses have been mainly reactive rather than constructive, and proposals have not been tested.

More tightly drawn contracts and greater managerial responsibilities could leave little time for senior medical staff to develop clinical practice and postgraduate activities. This would make it more difficult for the service to respond to patients' needs.

\section{Specific concerns}

The standing committee lists its concerns as follows.

Welcome, but scant, reference is made to postgraduate medical and dental education in Working for Patients; new entrepreneurial management systems could suppress educational activity in the same way as increased service demands; and research must be safeguarded as a vital part of postgraduate medical and dental education and it often arises from audit.

The maintenance of good programmes of training and continuing education is of major concern; these programmes depend on varied and well balanced clinical experience, gradual assumption of responsibility, and academic atmosphere to encourage high standards; proposals for funding by contract and self government in hospitals threaten this valuable educational network.

Working for Patients proposes that self governing hospitals will be free to set their own salary scales and conditions of appointment, a change that could jeopardise rotational training schemes between hospitals and threaten plans to reduce hours of work for junior doctors.

Medical staffing should be controlled centrally to preserve a coherent pattern of postgraduate training and ensure good quality of care.

Fragmentation of hospital and community services would adversely affect attempts to treat "the whole person" and prevent disease. Over $28 \%$ of all admissions to hospital are within the specialties that particularly need this type of integration: obstetrics, paediatrics, psychiatry, and geriatrics; in general

The Standing Committee on Postgraduate Medical Education has prepared a commentary on the white paper Working for Patients, and a shortened version is published here. The standing committee, which is appointed by the Secretary of State for Health, funded by the government, and chaired by Professor Dame Barbara Clayton, replaced the Council for Postgraduate Medical Education earlier this year.

The committee's terms of reference are: "To advise the Secretary of State on the delivery of postgraduate medical and dental education, taking into account both the standards promulgated by professional bodies and the potential difficulties of reconciling service and training needs; to identify particular problems and to develop realistic solutions to these in consultation with relevant interests; and to report regularly." practice children and elderly people account for more than $40 \%$ of all consultations.

More extensive use of medical audit is welcome and should be led by the profession; its potential for good could be lost, however, if the process becomes a tool of management using financial criteria and performance indicators.

The government should seek educational advice before acting on its proposals, and the interdependence of all specialties in using resources and providing care should be recognised.

Quality assurance should be extended to any hospital, including those outside the NHS, if doctors in training work in them.

Time spent on medical audit is not mentioned in the proposals for new consultant posts and this is cause for concern, as is the proposal that audit in primary care will be the responsibility of family practitioner committees and not local medical or district education committees.

Budget holding, the new contract for general practitioners, and the larger lists that will probably follow the increased contribution of capitation fees will be time consuming and deflect trainers from their educational roles.

Capital charges on assets and interest charged on debts could severely affect fácilities for education, such as libraries and postgraduate centres; these facilities should be exempt from capital stock taking.

The most critical component of postgraduate education is time: all doctors' job descriptions and contracts must contain the flexibility and time allowance to permit learning, teaching, and research if appropriate, and regional and district education committees should monitor provision of study leave and liaise regularly with health authorities and postgraduate committees.

Present financial provision for postgraduate education is inadequate; resources are difficult to cost and include hidden components such as careers counselling and supervision of those in training, but current facilities should be expanded after appropriate costing and data collection.

\section{Conclusions}

In conclusion the Standing Committee on Postgraduate Medical Education states:

- Responsibilities of health authorities for education and training should be spelt out

- Authorities should be required to plan and organise resources so that managers, doctors, dentists, and university staff can continue to develop and support postgraduate education

- The underlying motivation for all parties ought to be quality of medical care, and good quality of care is provided by many facets of postgraduate medical education but Working for Patients seeks it primarily through medical audit

- The present structure for the provision of postgraduate medical and dental education is a valuable base on which to develop and should be safeguarded and expanded

- Any changes should be implemented through negotiation with all staff currently involved in this educational system. 